\title{
Симультанний та двохетапний підходи в паціентів на метастатичний колоректальний рак із синхронним ураженням печінки
}

\begin{abstract}
Мета роботи: проаналізувати симультанний та двохетапний підходи в лікуванні пацієнтів на сМ-КРР, а також їхнє загальне та безрецидивне виживання.

Матеріали та методи. В дослідження включено 16 пацієнтів (10 чоловіків та 6 жінок) на сМ-КРР, котрим були виконані симультанні (14) та двохетапні (2) радикальні резекції в умовах Тернопільської університетської лікарні з 2013 по 2018 роки. Всі колоректальні резекції були виконані з дотриманням вимог онкологічного радикалізму (D3 лімфодисекція, тотальна меозоколон/мезоректумектомія). У 9 пацієнтів метастази в печінку локалізувались у лівій частці та у 7 пацієнтів у правій частці. Паренхімощадну техніку резекції печінки застосовано в 13 (81,3 \%) пацієнтів, тоді як анатомічну резекцію печінки виконано лише 3 (18,8 \%) пацієнтам. Ад’ювантну ПХТ отримали всі пацієнти, сумарно 6 курсів у режимі FOLFOX / XELOX.

Результати досліджень та їх обговорення. Ми не спостерігали жодного серйозного післяопераційного ускладнення чи смертності в 30-ти денний період. Середнє загальне та безрецидивне виживання у групі пацієнтів з регіонарними метастазами було

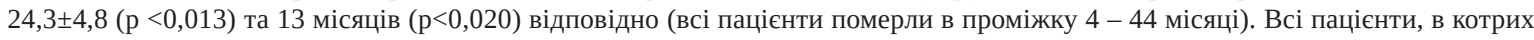
не було метастазів у регіонарні лімфатичні вузли, живі без ознак прогресії. Найдовший період безрецидивного виживання становить 80 місяців та спостерігається на момент написання статті у 3 пацієнтів (проміжок спостереження 11 - 80 місяців) Середнє загальне та безрецидивне виживання у групі пацієнтів з правобічною локалізацією КРР було 17,3 (р<0,51) і 9,2 місяців (р <0,51) відповідно. Симультанна резекція КРР та паренхімощадна техніка резекції печінки не демонструють збільшення кількісті тяжких післяопераційних ускладнень та 30-денної смертності, що також підтверджено нашим дослідженням.
\end{abstract}

Ключові слова: сМ-КРР; симультанні операції; загальне виживання; безрецидивне виживання

Постановка проблеми i аналіз останніх досліджень та публікацій. Метастатичний колоректальний рак із синхронним ураженням печінки (сМ-КРР) зустрічається приблизно у 25 \% хворих під час первинного діагностування [5]. Печінка - орган-мішень (60 \%) для дистальних метастазів КРР. Не зважаючи на всі хірургічні та онкологічні досягнення лише у 25 \% пацієнтів з сМ-КРР можливо виконати їх резекцію $[1,4]$. На сьогодні $€$ два основні підходи до лікування резектабельного сМ-КРР.

Прихильники симультанних резекцій апелюють наступними фактами: післяопераційний імунодефіцит сприяє появі нових метастатичних вогнищ, зменшення числа хірургічних втручань, зниження вартості лікування, можливе зменшення часу (курсів) ад’ювантної хіміотерапії [5].

Основні аргументи прихильників резекції первинної пухлини з відтермінованою резекцією печінки включають: локальний контроль після резекції первинної пухлини та джерела метастазів, зменшення числа серйозних ускладнень, які можуть виникнути після симультанних резекцій та “часовий тест”, оскільки в деяких пацієнтів після резекції первинного вогнища можуть 3'являтися метастази інших локалізацій в інтервалі відтермінованої резекції печінки [2, 3, 9].

Незважаючи на відсутність рандомізованих досліджень даної проблеми слід зазначити, що успіх у лікуванні залежить від локалізації первинного вогнища та біології пухлини [10].

Мета роботи: проаналізувати симультанний та двохетапний підходи в лікуванні пацієнтів на сM-КРР, а також їхнє загальне та безрецидивне виживання.

Матеріали і методи. У наше дослідження включені 16 пацієнтів (10 чоловіків та 6 жінок) на сМ-КРР, котрим були виконані симультанні та двохетапні радикальні резекції в умовах Тернопільської університетської лікарні з 2013 по 2018 роки. Всім 16 пацієнтам спершу виконано резекція КРР. Симультанні оперативні втручання виконано 14 пацієнтам, тоді як двохетапні втручання виконано в 2 пацієнтів. Одна пацієнтка перенесла два оперативних втручання: симультанна резекція та резекція метастазів у печінку після їх діагнос-

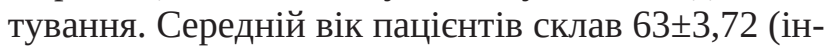
тервал 33-80). Первинна пухлина була локалізована в правих відділах ободової у 4 (25 \%) пацієнтів та у лівих відділах ободової кишки та прямої кишки у 12 (75 \%) пацієнтів. Всі коло-ректальні резекції були виконані з дотриманням канонів онкологічного радикалізму (D3 лімфодисекція, тотальна меозоколон/мезоректумектомія). В середньому кількість видалених лімфатичних вузлів була 19,72 \pm 1,43 (інтервал 12-31). Відповідно до класифікації TNM стадію T2 було виявлено в од- 
ного (6,3 \%) пацієнта, Т3 в 11 (68,8 \%) пацієнтів та Т4 в 4 (25 \%) пацієнтів. У 12 (75 \%) пацієнтів діагностовано високий (G1) ступінь диференціації аденокарциноми, тоді як помірний ступінь виявлено у 4 (25 \%) пацієнтів. Метастази в регіонарні лімфатичні вузли виявлено у 9 (56,3 \%) пацієнтів (N1 - 3 пацієнти та N2 - 6 пацієнтів).

У 9 (56,3 \%) пацієнтів метастази в печінку локалізувались у лівій долі та у 7 (43,8 \%) пацієнтів у правій частці. Відповідно до кількості метастатичних вогнищ (розмір від 20 до 150 мм): 13 (81,3 \%) пацієнтів мали одне вогнище, 2 (12,5 \%) пацієнтів мали два вогнища та 1 (6,3 \%) пацієнт мав 3 вогнища. Паренхімощадна техніка резекції печінки (II, III, IVa, IVb, V, VI та VII сегменти) була застосована у 13 (81,3 \%) пацієнтів, тоді як анатомічна резекція печінки (ліва частка, II-III та VIII сегменти) була виконана лише 3 (18,8 \%) пацієнтам (рис. 1-3).
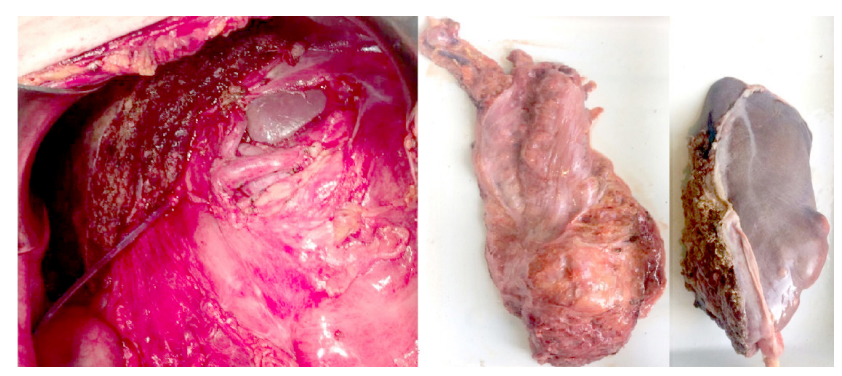

Рис. 1. Лівобічна гемігепатектомія та низька передня резекція прямої кишки.

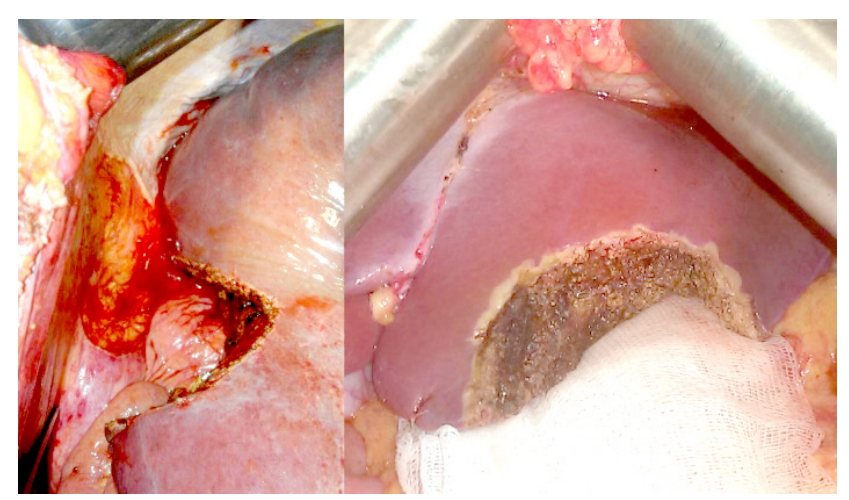

Рис. 2. Атипова резекція VI та III сегментів печінки.

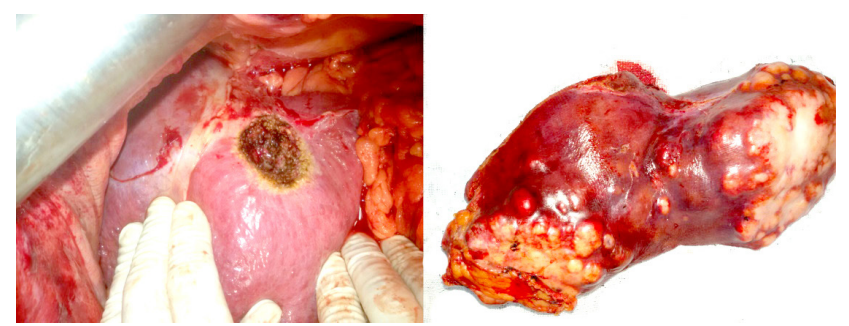

Рис. 3. Атипова резекція II сегмента та макропрепарат видалених II та III сегментів печінки.
Неоад’ювантна ПХТ була призначена 5 (31,3 \%) пацієнтам. Ад’ювантну ПХТ отримали всі пацієнти, сумарно 6 курсів у режимі FOLFOX / XELOX. 3 (18,8 \%) пацієнтам після прогресування захворювання призначено другу лінію ПХТ. 6 (37,5 \%) пацієнтів із раком прямої кишки отримали передопераційну променеву терапію на ділянку первинної пухлини прямої кишки (СВД 30 Гр). У 2 пацієнтів (через 2 та 5 років після операції) діагностували рак легень (гістологічно верифіковано плоскоклітинний рак) та в 1 пацієнта (через 7 років) виявили рак привушної залози.

Статистичний аналіз. Дані пацієнтів проспективно були зібрані в базу та проведено ретроспективний аналіз. Порівняння кривих виживання проводилося попарно за допомогою логрангового тесту Мантела-Кокса в статистичному пакеті SPSS. В цій програмі ми застосували процедуру побудови кривих виживання за допомогою метода Каплан-Майєра.

Результати досліджень та їх обговорення. Ми не спостерігали жодного серйозного післяопераційного ускладнення чи смертності в 30 -денний період. В 1 пацієнтки діагностовано ілеофеморальний тромбоз в ранньому післяопераційному періоді, котрий було консерватино ліквідовано. Середня тривалість перебування пацієнтів у стаціонарі становила 8,7 дня. Всі резекції печінки та КРР були виконані за допомогою методу Келліклазія з чистим R0 краєм. Під час симультанного операційного втручання середня інтраопераційна крововтрата склала 251 мл (30-1100 мл), а тривалість становила 206 хвилин (160-330 хв). Згідно із шкалою ASA: 1 - 4 (25\%) пацієнт, 2 9 (56,3 \%) пацієнтів, 3-2 (12,5 \%) пацієнти, 4-1 (6,3%) пацієнт.

Під час ретроспективного аналізу загального та безрецидивного виживання ми поділили пацієнтів на 2 підгрупи за локалізацією пухлини та статусом регіонарних лімфатичних вузлів. Середнє загальне та безрецидивне виживання у групі пацієнтів з регіонарними метастазами було 24,3 $\pm 4,8(\mathrm{p}<0,013)$ та 13 місяців (р <0,020) відповідно (всі пацієнти померли в проміжку 4 - 44 місяці), (рис. 4). Всі пацієнти, в котрих не було метастазів в регіонарні лімфатичні вузли, живі без ознак прогресії. Найдовший період безрецидивного виживання становить 80 місяців та спостерігається на момент написання статті у 3 пацієнтів (проміжок спостереження 11 80 місяців). Середнє загальне та безрецидивне виживання у групі пацієнтів з правобічною локалізацією КРР було 17,3 (р <0,51) і 9,2 місяця (р <0,51) відповідно (рис. 5). 

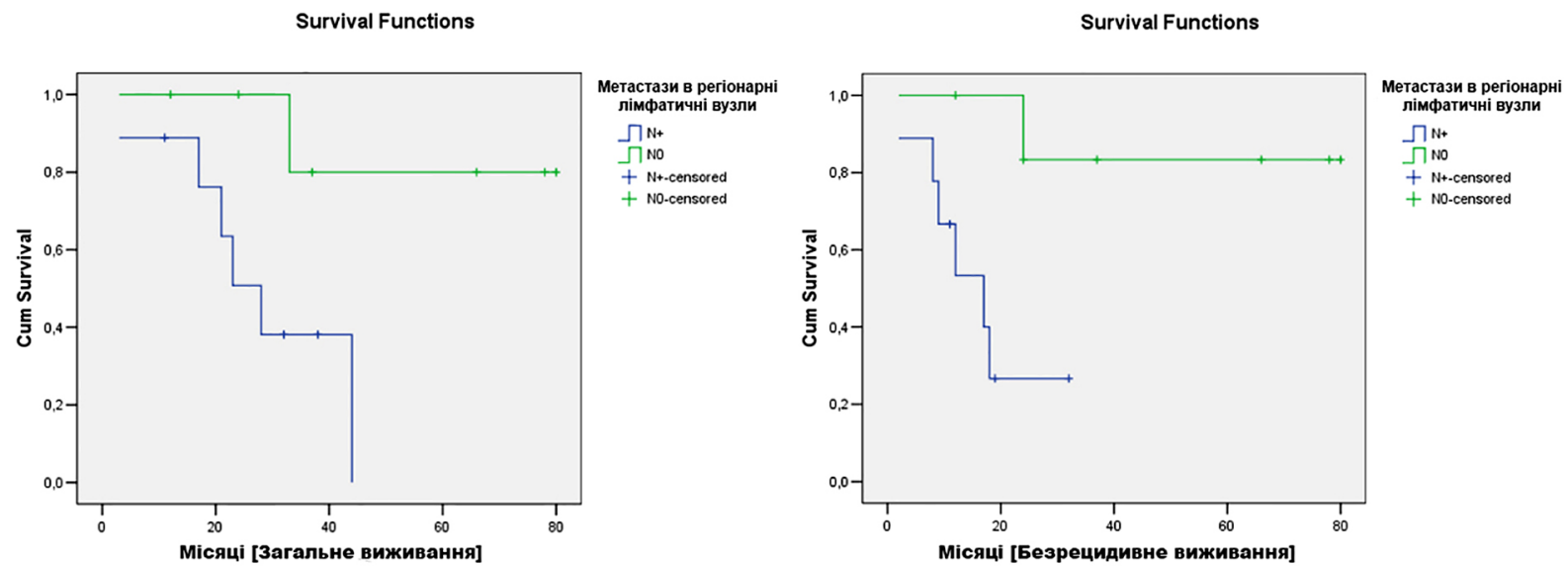

Рис. 4. Криві Каплан-Майєра безрецидивного $(\mathrm{p}<0,013)$ та загального виживання $(\mathrm{p}<0,020)$ враховуючи статус регіонарних лімфатичних вузлів.
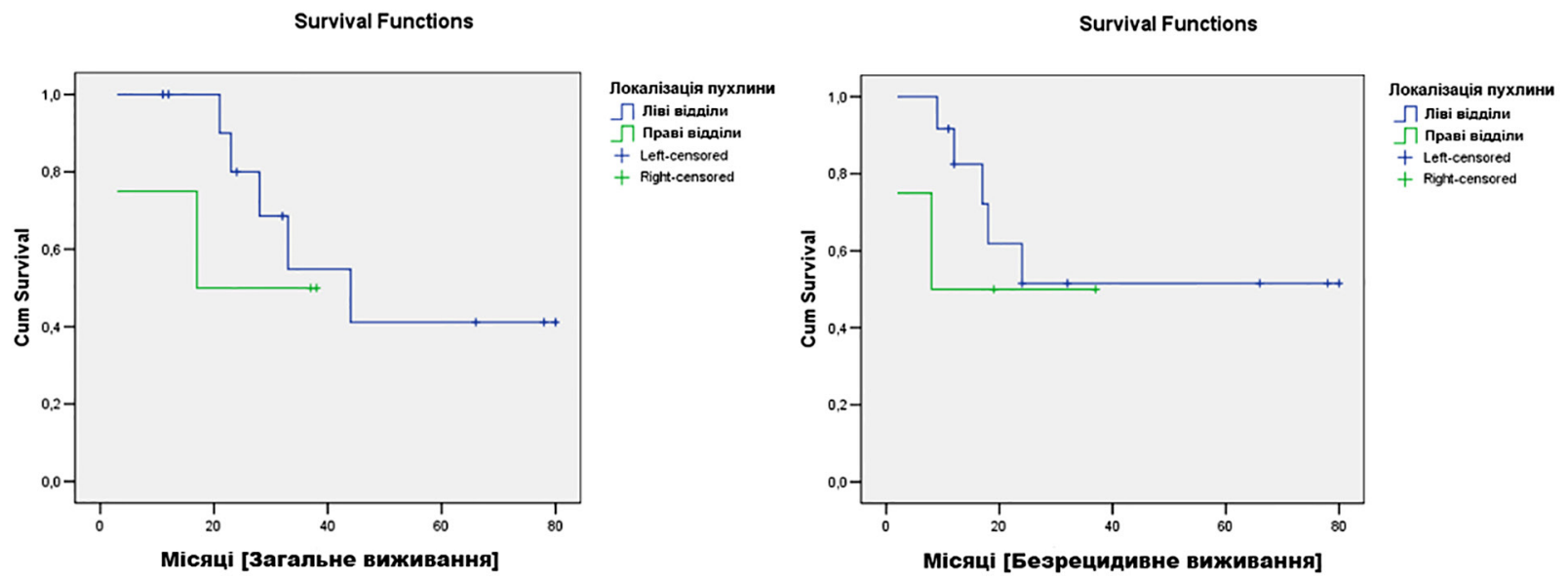

Рис. 5. Криві Каплан-Майєра безрецидивного ( $<0,51)$ та загального виживання (p<0,51) враховуючи локалізацію пухлинного процесу.

Ретроспективно встановлено, що загальне 5-річне виживання в групі без регіонарних метастазів становило $(80 \pm 18) \%$, а для групи метастазами $0 \%$. Загальне безрецидивне 5-річне виживання в групі без регіонарних метастазів становило $(83 \pm 15) \%$, а для групи метастазами - 0 \%.

Ретроспективно встановлено, що загальне 5-річне виживання в групі пацієнтів із правобічною локалізацією КРР становило (33 27$) \%$, а для групи пацієнтів 3 лівобічною локалізацією КРР станови-

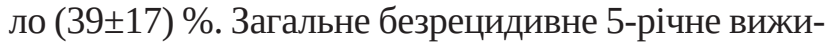
вання в групі пацієнтів з правобічною локалізацією

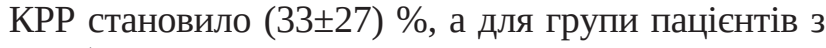
лівобічною локалізацією КРР - (46士17) \%.

Виконання відтермінованої резекції печінки після резекції первинної пухлини сM-КРP із метою призначення тривалої хіміотерапії має сумнівну ефективність через високу гепатотоксичність препаратів. У недавніх опублікованих до- слідженнях зберігається тенденція до збільшення кількості симультанних операцій у пацієнтів на сМ-КРР [9]. Такі оптимальні фактори, як лівобічна локалізація КРР, паренхімощадна техніка резекції печінки, поверхневі та монолобарні метастази, задовільний загальний статус без тяжких супутніх захворювань $€$ найкращою таргетною групою пацієнтів для виконання симультанної операції [7, 9]. Більше того, така комбінація факторів може покращити онкологічні результати лікування пацієнтів на сМ-КРР [3].

Симультанна резекція КРР та паренхімощадна техніка резекції печінки не демонструють збільшення кількісті тяжких післяопераційних ускладнень та 30-денної смертності [9], що також підтверджено нашим дослідженням. Більше того такий підхід дозволяє покращити результати виживання пацієнтів даної групи [6]. Тоді як симультанні колоректальні резекції та великі анатомічні 
резекції печінки є дискусійним та сумнівно-безпечним підходом, що може потенційно збільшити частоту неспроможності швів анастомозу та печінкової недостатністі, тому потребує детального відбору таких пацієнтів [8].

У нашому дослідженні ми виявили декілька прогностичних факторів для загального та безрецидивного виживання пацієнтів на сМ-КРР. Стосовно локалізації пухлини - факт іншої біології пухлини та відповідно гіршого прогнозу у пацієнтів з правобічною локалізацією КРР у світовій літературі широко дискутований та підтверджений [10]. Ми бачимо подібну ситуацію в нашій невеликій групі пацієнтів (рис. 4). Декілька етіологічних факторів цього чітко окреслені: пухлини правих відділів ободової кишки мають пізнішу клінічну маніфестацію, більш старший вік пацієнтів та більш агресивна біологія пухлин порівняно 3 пухлинами лівих відділів ободової кишки [4].

Очевидний негативний прогноз в групі пацієнтів із регіонарними метастазами [1], також підтверджений нашим аналізом (рис. 3). Середнє за-

\section{СПИСОК ЛІТЕРАТУРИ}

1. Analysis of prognostic factors for resected synchronous and metachronous liver metastases from colorectal cancer / I. Bartolini, M. N. Ringressi, F. Melli [et al.] // Gastroenterology Research and Practise. - 2018. - Vol. 11. - P. 7.

2. Actual 10-year survival after hepatic resection of colorectal liver metastases: what factors preclude cure? / J. M. Creasy, E. Sadot, B. G. Koerkamp [et al.] // Surgery. - 2018. - Vol. 163 (6). - P. 1238-1244.

3. Parenchymal sparing surgery for the surgical treatment of multiple colorectal liver metastases is a safer approach than major hepatectomy not impairing patients' prognosis: a bi-institutional propensity score-matched analysis / M. Donadon, M. Cescon, A. Cucchetti [et al.] // Digestive Surgery. - 2017. - Vol. 35 (4). - P. 342-349.

4. Colorectal cancer liver metastases - a population-based study on incidence, management and survival / J. Engstrand, H. Nilsson, C. Strömberg [et al.] // BMC Cancer. - 2018. - Vol. 18 (1). - P. 78.

5. Simultaneous versus delayed hepatectomy for synchronous colorectal liver metastases: a systematic review and meta-analysis / P. Gavriilidis, R. P. Sutcliffe, J. Hodson [et al.] // HPB. 2018. - Vol. 20 (1). - P. 11-19.

\section{REFERENCES}

1. Bartolini, I., Ringressi, M.N., Melli, F., Risaliti, M., Brugia, M., Mini, E., \& Taddei, A. (2018). Analysis of prognostic factors for resected synchronous and metachronous liver metastases from colorectal cancer. Gastroenterology Research and Practise, 11, 7.

2. Creasy, J.M., Sadot, E., Koerkamp, B.G., Chou, J.F., Gonen, M., Kemeny, N.E., ..., \& D'Angelica, M.I. (2018). Actual 10-year survival after hepatic resection of colorectal liver metastases: what factors preclude cure? Surgery, 163, 6, 1238-1244. гальне та безрецидивне 5-річне виживання пацієнтів 3 ураженими регіонарними лімфатичними вузлами було 24,3ะ4,8 та 13 місяців відповідно.

Чистота країв резекції також дуже важливий фактор, який незалежно асоціюється з загальним виживанням [8], попри це ми досягли R0 статусу у всіх пацієнтів.

Висновки. 1. Симультанна резекція КРP та паренхімощадна техніка резекції печінки є агресивним, онкологічно виправданим та економічно ефективним підходом у радикальному лікуванні пацієнтів із сM-КРP.

2. У нашому дослідженні ми не спостерігали зростання післяопераційних ускладнень після симультанних резекцій порівняно з двохетапним підходом.

3. Категорія пацієнтів із правобічною локалізацією КРР та позитивним статусом регіонарних лімфатичних вузлів мають статистично значущий гірший прогноз, погане загальне та безрецидивне 5-річне виживання.

6. Parenchymal-sparing hepatectomy in colorectal liver metastasis improves salvageability and survival / Y. Mise, T. A. Aloia, K. W. Brudvik [et al.] // Annals of Surgery. - 2016. - Vol. 263 (1). - P. 146-152.

7. Perioperative FOLFOX4 chemotherapy and surgery versus surgery alone for resectable liver metastases from colorectal cancer (EORTC 40983): long-term results of a randomised, controlled, phase 3 trial / B. Nordlinger, H. Sorbye, B. Glimelius [et al.] // The Lancet Oncology. - 2013. - Vol. 14 (12). - P. 1208-1215.

8. Short-term outcomes after simultaneous colorectal and major hepatic resection for synchronous colorectal liver metastases / Y. Ono, A. Saiura, J. Arita [et al.] // Digestive Surgery. - 2017. Vol. 34 (6). - P. 447-454.

9. The timing of liver resection in patients with colorectal cancer and synchronous liver metastases: a population-based study of current practice and survival / A. E. Vallance, J. van der Meulen, A. Kuryba [et al.] // Colorectal Disease. - 2018. - Vol. 20(6). - P. 486-495.

10. The worse prognosis of right-sided compared with left-sided colon cancers: a systematic review and metaanalysis / M. Yahagi, K. Okabayashi, H. Hasegawa, [et al.] // Journal of Gastrointestinal Surgery. - 2016. - Vol. 20 (3). - P. 648-655.

3. Donadon, M., Cescon, M., Cucchetti, A., Cimino, M., Costa, G., Pesi, B., ..., \& Torzilli, G. (2017). Parenchymal sparing surgery for the surgical treatment of multiple colorectal liver metastases is a safer approach than major hepatectomy not impairing patients’ prognosis: a bi-institutional propensity score-matched analysis. Digestive Surgery, 35 (4), 342-349.

4. Engstrand, J., Nilsson, H., Strömberg, C., Jonas, E., \& Freedman, J. (2018). Colorectal cancer liver metastases - a population- 
based study on incidence, management and survival. BMC Cancer, 18, 1, 78.

5. Gavriilidis, P., Katsanos, K., Sutcliffe, R.P., Simopoulos, C., Azoulay, D., \& Roberts, K.J. (2018). Simultaneous versus delayed hepatectomy for synchronous colorectal liver metastases: a systematic review and meta-analysis. HPB, 20 (1), 11-19. 6. Mise, Y., Aloia, T.A., Brudvik, K.W., Schwarz, L., Vauthey, J.N., \& Conrad, C. (2016). Parenchymal-sparing hepatectomy in colorectal liver metastasis improves salvageability and survival. Annals of Surgery, 263 (1), 146-152.

7. Nordlinger, B., Sorbye, H., Glimelius, B., Poston, G.J., Schlag, P.M., Rougier, P., ..., \& Gruenberger, T. (2013). Perioperative FOLFOX4 chemotherapy and surgery versus surgery alone for resectable liver metastases from colorectal cancer (EORTC 40983): long-term results of a randomised, controlled, phase 3 trial. The Lancet Oncology, 14, 12, 1208-1215.

8. Ono, Y., Saiura, A., Arita, J., Takahashi, Y., Takahashi, M., \& Inoue, Y. (2017). Short-term outcomes after simultaneous colorectal and major hepatic resection for synchronous colorectal liver metastases. Digestive Surgery, 34 (6), 447-454.

9. Vallance, A.E., van der Meulen, J., Kuryba, A., Charman, S.C., Botterill, I.D., Prasad, K.R., ..., \& Walker, K. (2018). The timing of liver resection in patients with colorectal cancer and synchronous liver metastases: a population-based study of current practice and survival. Colorectal Disease, 20 (6), 486-495.

10. Yahagi, M., Okabayashi, K., Hasegawa, H., Tsuruta, M., \& Kitagawa, Y. (2016). The worse prognosis of right-sided compared with left-sided colon cancers: a systematic review and metaanalysis. Journal of Gastrointestinal Surgery, 20 (3), 648655.

Отримано 25.10.2019

Електронна адреса для листування: stepan_grytsenko@ukr.net

Y. M. GRYTSENKO, A. D. BEDENIUK, S. Y. GRYTSENKO

I. Horbachevsky Ternopil National Medical University

\title{
SIMULTANEOUS AND TWO-STAGE APPROACHES IN PATIENTS WITH COLORECTAL CANCER AND SYNCHRONOUS LIVER METASTASIS
}

\begin{abstract}
The aim of the work: to analyze simultaneous and two-stage approaches in the treatment of patients with colorectal cancer and synchronous liver metastasis, as well as their overall and disease-free survival.

Materials and Methods. 16 patients (10 men and 6 women) patients with colorectal cancer and synchronous liver metastasis who underwent simultaneous (14) and two-stage (2) radical resections at Ternopil University Hospital from 2013 to 2018. All colorectal resections were performed in accordance with the requirements of oncological radicalism (D3 lymphodissection, total mesocolic/ mesorectal excision). In 9 patients, liver metastasis were localized in the left lobe and in 7 patients - in the right lobe. Parenchymalsparing technique for liver resection was used in 13 (81.3\%) patients, while anatomic resection of the liver was performed in $3(18.8 \%)$ patients. Adjuvant chemptherapy was given to all patients ( 6 courses of FOLFOX or XELOX).

Results and Discussion. We did not observe any severe postoperative complication or 30-day mortality. The median overall and disease-free survival in the group of patients with regional metastasis was $(24.3 \pm 4.8)(\mathrm{p}<0.013)$ and 13 months $(\mathrm{p}<0.020)$ respectively (all patients died between 4 and 44 months). All patients who had no regional lymph nodes metastasis are still alive without signs of progression. The longest overall survival period is 80 months and are observed at the time of writing of this article in 3 patients (followup period 11-80 months). The median overall and disease-free survival in the patients with right-sided CRC was $17.3(\mathrm{p}<0.51)$ and 9.2 months ( $<0.51$ ), respectively. Simultaneous CRC resection and parenchymal-sparing liver resection do not show an increase in the number of severe postoperative complications and 30-day mortality, which is also confirmed by our study.
\end{abstract}

Key words: synchronous liver metastasis of CRC; simultaneous operations; overall survival; disease-free survival.

И. М. ГРИЦЕНКО, А. Д. БЕДЕНЮК, С. И. ГРИЦЕНКО

Тернопольский национальный медицинский университет имени И. Я. Горбачевского МОз Украины

\section{СИМУЛЬТАННЫЙ И ДВУХЭТАПНЫЙ ПОДХОДЫ У ПАЦИЕНТОВ С МЕТАСТАТИЧЕСКИМ КОЛОРЕКТАЛЬНЫМ РАКОМ И СИНХРОННЫМ ПОРАЖЕНИЕМ ПЕЧЕНИ}

\footnotetext{
Цель работы: проанализировать симультанный и двухэтапный подходы в лечении пациентов на сМ-КРР, а также их общую и безрецидивную выживаемость.

Материалы и методы. В исследование включено 6 пациентов (10 мужчин и 6 женщин) на сМ-КРР, которым были выполнены симультанные (14) и двухэтапные (2) радикальные резекции в условиях Тернопольской университетской больницы с 2013 по 2018 годы. Все колоректальные резекции были выполнены с соблюдением онкологического радикализма (D3 лимфодисекция, тотальная меозоколон/мезоректумэктомия). В 9 пациентов метастазы в печень локализовались в левой доле и у 7 пациентов в правой доле. Паренхимощадящая техника резекции печени была применена в 13 (81,3 \%) пациентов, в то время как
} 


\section{З ДОСВІДУ РОБОТИ}

анатомическая резекция печени была выполнена 3 (18,8 \%) пациентам. Адъювантную химиотерапию получили все пациенты, суммарно 6 курсов в режиме FOLFOX/XELOX.

Результаты исследований и их обсуждение. Мы не наблюдали ни одного серьезного послеоперационного осложнения или смертности в 30-дневный период. Средняя общая и безрецидивная выживаемость в группе пациентов с регионарными метастазами была $24,3 \pm 4,8$ ( $<<0,013$ ) и 13 месяцев ( $<0,020$ ) соответственно (все пациенты умерли в промежутке 4-44 месяца). Все пациенты, в которых не было метастазов в регионарные лимфатические узлы, живые без признаков прогрессии. Самый длинный период безрецидивного выживания составляет 80 месяцев и наблюдается на момент написания статьи у 3 пациентов (промежуток наблюдения 11-80 месяцев). Средняя общая и безрецидивная выживаемость в группе пациентов с правосторонней локализацией КРР была 17,3 (р <0,51) и 9,2 месяцев (р <0,51) соответственно. Симультанная резекция КРР и паренхимощадящая техника резекции печени не демонстрируют увеличение количества тяжелых послеоперационных осложнений и 30 -дневной смертности, что также подтверждено нашим исследованием.

Ключевые слова: сМ-КРР; симультанные операции; общая выживаемость; безрецидивная выживаемость. 